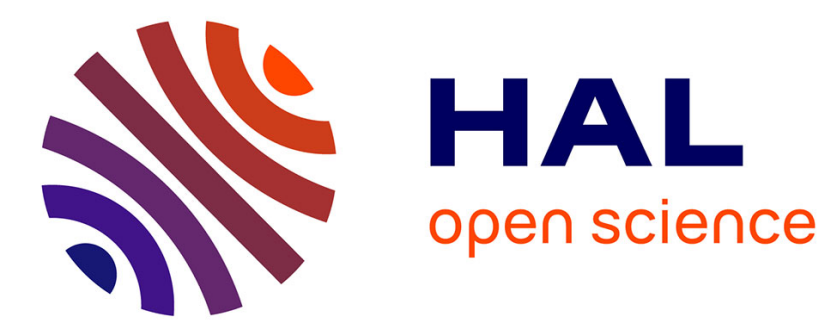

\title{
Serum Phosphate Kinetics in Acute Kidney Injury After Cardiac Surgery: An Observational Study
}

\author{
Marine Saour, Norddine Zeroual, Jérôme Ridolfo, Erika Nogué,
} Marie-Christine Picot, Philippe Gaudard, Pascal Colson

\section{- To cite this version:}

Marine Saour, Norddine Zeroual, Jérôme Ridolfo, Erika Nogué, Marie-Christine Picot, et al.. Serum Phosphate Kinetics in Acute Kidney Injury After Cardiac Surgery: An Observational Study. Journal of Cardiothoracic and Vascular Anesthesia, In press, 10.1053/j.jvca.2020.05.023 . hal-02908030

\section{HAL Id: hal-02908030 \\ https://hal.science/hal-02908030}

Submitted on 29 Jul 2020

HAL is a multi-disciplinary open access archive for the deposit and dissemination of scientific research documents, whether they are published or not. The documents may come from teaching and research institutions in France or abroad, or from public or private research centers.
L'archive ouverte pluridisciplinaire HAL, est destinée au dépôt et à la diffusion de documents scientifiques de niveau recherche, publiés ou non, émanant des établissements d'enseignement et de recherche français ou étrangers, des laboratoires publics ou privés. 


\title{
Serum Phosphate Kinetics in Acute Kidney Injury After Cardiac Surgery: An Observational Study
}

\author{
Marine Saour, MD ${ }^{*, 1}$, Norddine Zeroual, MD*, \\ Jérôme Ridolfo, $\mathrm{MD}^{*}$, Erika Nogue ${ }^{\dagger}$, Marie-Christine Picot, $\mathrm{MD}^{\dagger}$, \\ Philippe Gaudard, MD, $\mathrm{PhD}^{*, \ddagger, 2}$, Pascal H. Colson, $\mathrm{MD}^{*, \S, 2}$ \\ *Department of Anesthesiology and Critical Care Medicine, Arnaud de Villeneuve Hospital, CHU Montpellier, \\ Montpellier, France \\ ${ }^{\dagger}$ Clinical Research and Epidemiology Unit, CHU Montpellier, Montpellier, France \\ ${ }^{\ddagger}$ Montpellier University, CNRS, INSERM, PhyMedExp, Montpellier, France \\ ${ }^{\S}$ Montpellier University, CNRS, INSERM, Institut de Génomique Fonctionnelle, Montpellier, France
}

Objective: Acute kidney injury (AKI) is a common complication after cardiac surgery and may affect prognosis. Serum phosphate (SPh) elevation is well-known to occur after AKI but not well-documented. The aim of the present study was to describe SPh changes during AKI after cardiac surgery and to assess the accuracy for the diagnosis of AKI severity and recovery.

Design: Prospective, single center, observational study.

Setting: Intensive care unit of a tertiary university hospital.

Participants: All patients admitted consecutively to the intensive care unit between February 2015 and March 2016.

Measurements and Main Results: AKI was defined according to Kidney Disease Improving Global Outcomes criteria and classified as nonsevere (stage 1) and severe (stages 2 and 3). Receiver operating characteristic curve analysis was conducted to test reliability of SPh for AKI severity and recovery. AKI occurred in 86 of the 260 patients included (33\%) in the study; 58 (67\%) experienced nonsevere AKI, and 28 (33\%) experienced severe AKI. A significant elevation of SPh values was observed in AKI patients, which peaked at 48 hours. At this time, an SPh of $1.33 \mathrm{mmol} / \mathrm{L}$ demonstrated a good accuracy for AKI severity, with an area under the curve of 0.91 (95\% confidence interval 0.82-1.00). For kidney recovery, a $25 \% \mathrm{SPh}$ decrease 24 hours after the peak had a positive predictive value of $100 \%$, and a $2.5 \%$ decrease allowed for the reclassification of patients when the serum creatinine had not decreased enough.

Conclusions: The results showed that SPh changes closely follow AKI severity and kidney recovery after cardiac surgery. In addition to serum creatinine, this simple biological marker may help predict early favorable outcome.

Key Words: Acute kidney injury; Phosphate; Cardiac surgery

ACUTE kidney injury (AKI) is a common complication after cardiac surgery, affecting up to $20 \%$ to $40 \%$ of patients, with $3 \%$ requiring renal replacement therapy (RRT). ${ }^{1-3}$ AKI is a major concern because postoperative

\footnotetext{
${ }^{1}$ Address reprint requests to Marine Saour, MD, Department of Anesthesiology and Critical Care Medicine, Arnaud de Villeneuve Hospital, CHU Montpellier, 371 Avenue Doyen Giraud, 34295 Montpellier Cedex 5, France.

E-mail address: m-saour@chu-montpellier.fr (M. Saour).

${ }^{2}$ P. Gaudard and P.H. Colson contributed equally to the present study.
}

AKI jeopardizes short- and long-term prognosis, mostly when AKI is severe. ${ }^{3}$ In addition to predictive scores, ${ }^{4,5}$ various new biomarkers, such as neutrophil gelatinase-associated lipocalin have been tested to improve AKI prediction with good success, but they are not able to predict AKI recovery nor are they helpful for monitoring AKI evolution. ${ }^{6-11}$ Monitoring AKI evolution is challenging because it may significantly influence patient management, including the decision for RRT and intensive care unit (ICU) length of stay. ${ }^{12}$ 
In addition to renal filtration impairment, AKI is associated with a variety of biochemical abnormalities as a result of impairment of tubular function that leads to reabsorption/ excretion failure of various ions and acid-base imbalance. ${ }^{13,14}$ Serum creatinine ( $\mathrm{SCr}$ ) elevation has been included in the criteria to define and classify AKI. ${ }^{15}$ However, SCr elevation reflects a delayed impairment of renal filtration and may not be an accurate marker of tubular dysfunction. ${ }^{14,16}$ Serum phosphate $(\mathrm{SPh})$ is a common anion, and its regulation depends on kidney function. ${ }^{17}$ In chronic kidney disease (CKD), SPh increase has been observed at an even relatively modest reduction of renal function ${ }^{18}$ and is considered as a major prognosis factor of CKD aggravation, dialysis requirement, and mortality. ${ }^{18-20}$

Postoperative management after cardiac surgery requires regular biologic control, including $\mathrm{SPh}$, because hypophosphatemia may be associated with a complicated postoperative outcome. $^{21}$ During routine clinical practice, the authors of the present study had observed that SPh changes during AKI followed renal function decline and recovery; however, to their knowledge, these variations have never been studied thoroughly. ${ }^{13}$ Because SPh depends on minute-to-minute regulation by the kidney, a close correlation between SPh changes and AKI evolution might be expected.

Therefore, the authors designed a prospective, observational study on SPh concentration after cardiac surgery to assess its changes during AKI. The second objective of the study was to assess whether $\mathrm{SPh}$ is reliable for assessing AKI severity and recovery.

\section{Methods}

\section{Trial Design}

The present clinical study was a prospective, observational, single-center study (NCT 0290031) and was approved by the Institutional Review Board (Comité de Protection des Personnes régional Sud-Méditerranée I [number 2015-A00781-48]). Because of the observational nature of the study, the need for patient informed consent was waived.

\section{Participants}

All adult patients ( $\geq 18$ years old) admitted consecutively to the ICU after cardiac surgery with cardiopulmonary bypass (CPB) were included. Patients with the following characteristics were not included: (1) severe chronic renal disease (defined as glomerular filtration rate (GFR) $\leq 15$ $\mathrm{mL} / \mathrm{min} / 1.73 \mathrm{~m}^{2}$ ) or preoperative AKI; (2) kidney transplantation or nephrectomy or single kidney disease; (3) perioperative hemofiltration; (4) left ventricular assist device; or (5) surgical revision within the first 48 hours after surgery.

\section{Study Settings}

The study was conducted in a 14-bed cardiothoracic ICU at a university hospital.

\section{Interventions}

The usual cardiac treatment was maintained until the day before surgery. Perioperative management (anesthesia, CPB, and cardioplegia) was standardized for all the patients. CPB was instituted with a membrane oxygenator primed with $1.5 \mathrm{~L}$ of crystalloid (Isofundin; B. Braun, Melsungen, Germany), and body temperature was maintained at $34^{\circ} \mathrm{C}$ to $36^{\circ} \mathrm{C}$. After aortic clamping, a hyperkalemic blood cardioplegic solution was infused into the aortic root of the aorta until myocardial arrest. A nonpulsatile pump flow rate was maintained between 2.2 and $2.6 \mathrm{~L} / \mathrm{min} / \mathrm{m}^{2}$, provided that the $\mathrm{SvO}_{2}$ monitored on the pump exceeded $60 \%$. Crystalloid solution (balanced crystalloid solution) could be added to maintain pump flow, and blood products were used to maintain a hemoglobin level $>7 \mathrm{~g} / \mathrm{dL}$ during $\mathrm{CPB}$ and $>8 \mathrm{~g} / \mathrm{dL}$ after CPB. Hypotension (mean arterial pressure $[\mathrm{MAP}] \leq 60 \mathrm{mmHg}$ ) was treated with the continuous intravenous administration of norepinephrine to maintain MAP > $60 \mathrm{mmHg}$. After completion of the surgical procedure, patients were weaned from $\mathrm{CPB}$ when a rectal temperature of $36^{\circ} \mathrm{C}$ had been reached.

In the ICU, inotropic support (dobutamine) was used to achieve a cardiac index $\geq 2.2 \mathrm{~L} / \mathrm{min} / \mathrm{m}^{2}$, as assessed by thermodilution (pulmonary catheter) or echocardiography (aortic flow measured by pulsed Doppler time- velocity integral), with normal left ventricular filling pressure. Hypotension (MAP $\leq 60 \mathrm{mmHg}$ ) without cardiogenic shock features (cardiac index $>2.2 \mathrm{~L} / \mathrm{min}$ / $\mathrm{m}^{2}$ ) was treated with continuous intravenous administration of norepinephrine to restore MAP to $>60 \mathrm{mmHg}$, and repeated boluses of morphine were used to keep patients pain free. Weaning from the ventilator was started during the emergence of anesthesia, and extubation was performed when hemodynamics were stable and normothermia was maintained for $\geq 1$ hour.

Kidney function assessment included $\mathrm{SCr}$ and $\mathrm{SPh}$ measurements the day before surgery (baseline value), at ICU admission, every 12 hours during ICU stay (every morning and evening), every morning up to postoperative day 5 , and then at the discretion of the physician in charge of the patient as per the authors' routine practice. EuroSCORE II $^{22}$ was used to assess the cardiac surgical risk, and the Simplified Acute Physiology Score $^{23}$ was used to assess the mortality risk in the ICU.

\section{Study Outcomes}

The primary outcome was to measure SPh changes during AKI after cardiac surgery. SPh was measured during the first 5 days after surgery to detect the peak value, which then was considered as the AKI reference value. AKI was defined according to the Kidney Disease Improving Global Outcomes (KDIGO) guidelines, except that urine output was not used to classify patients into the 3 following KDIGO stages ${ }^{15}$ : stage $1, \mathrm{SCr}$ at 1.5 - to1.9 times baseline or an $\mathrm{SCr}$ increase $\geq 26.5 \mu \mathrm{mol} / \mathrm{L}$; stage 2, $\mathrm{SCr}$ at 2.0- to- 2.9 times baseline; and stage 3, Scr at 3.0 times the baseline or an $\mathrm{SCr}$ increase $\geq 353.6 \mu \mathrm{mol} / \mathrm{L}$. A subgroup analysis also was performed in patients with preoperative CKD defined by an $<60 \mathrm{~mL} / \mathrm{m} / 1.73 \mathrm{~m}^{2}$. 
The secondary outcomes included SPh accuracy for diagnosis of AKI severity and recovery. AKI severity was graded as nonsevere (stage 1) and severe AKI (stages 2 and 3). RRT was initiated according to guidelines, independent of $\mathrm{SPh}$ values. Because of the absence of a consensus definition, renal recovery was defined arbitrarily as an SCr equal to or less than the preoperative $\mathrm{SCr}+26.5 \mu \mathrm{mol} / \mathrm{L}$ at hospital discharge. Recovery was studied only in AKI patients without RRT.

\section{Statistical Analysis}

The sample size was estimated from an expected AKI incidence of $30 \%$ according to a study in which neutrophil gelatinase-associated lipocalin was used to diagnose AKI, with a sensitivity (Se) of 0.7 and false positive rate at $0.1 .{ }^{15}$ For a study power of $90 \%$ and a risk $\alpha$ at $5 \%, 88$ patients with AKI and 176 patients without AKI were needed (total 264). Quantitative data are expressed as mean \pm standard deviation or median [Q25-Q75] and categorical variables as the number of patients and percentage.

Patient characteristics were described and were compared between groups using the chi-square or Fisher exact test for categorical variables and Student or Wilcoxon Mann-Whitney test for continuous variables. Holm's correction was used for multiple comparisons. Receiver operating characteristic (ROC) curves were used to determine the $\mathrm{SPh}$ and $\mathrm{SCr}$ cutoff of severe AKI (KDIGO stages 2 and 3) at their peak value after surgery. The area under the ROC curve (AUC) was calculated, along with its 95\% confidence interval (CI). The cutoff was determined using the Youden index to optimize both Se and specificity (Sp), and the performances associated were reported ( $\mathrm{Se}, \mathrm{Sp}$, positive predictive value [PPV], and negative predictive value $[\mathrm{NPV}])$. ROC analyses also were used to study the performance of the relative decreases of $\mathrm{SCr}$ and $\mathrm{SPh}$ after the peak (value at $24 \mathrm{~h}$ after the peak - peak value/peak value) to assess predictability of renal recovery. The AUCs were compared using a nonparametric approach. The statistical significance threshold was set at 5\%. Statistical analysis was performed using SAS Enterprise Guide, Version 7.3 (SAS Institute, Cary, NC).

\section{Results}

\section{Study Population and AKI Incidence}

The study flowchart is shown in Fig 1. During the study period between February 2015 and March 2016, 260 patients were included. Most participants were male $(73.5 \%)$. Preoperative CKD was found in $33.1 \%(\mathrm{n}=86)$ of the population (Table 1). AKI occurred in 86 patients $(33.1 \%)-58(22.3 \%)$ in stage $1,11(4.2 \%)$ in stage 2 , and $17(6.6 \%)$ in stage 3 -and of all the patients, $9(3.5 \%)$ required RRT, which was started with a median delay of 1.6 days. ${ }^{1,2}$ AKI patients were sicker, had longer surgery times, and needed more postoperative support, which resulted in a longer ICU stay and greater mortality rates (see Table 1). AKI occurred early, in the first 24 hours after surgery for 65 patients (75.6\%), especially for AKI stages 2 and 3 (Fig 2).

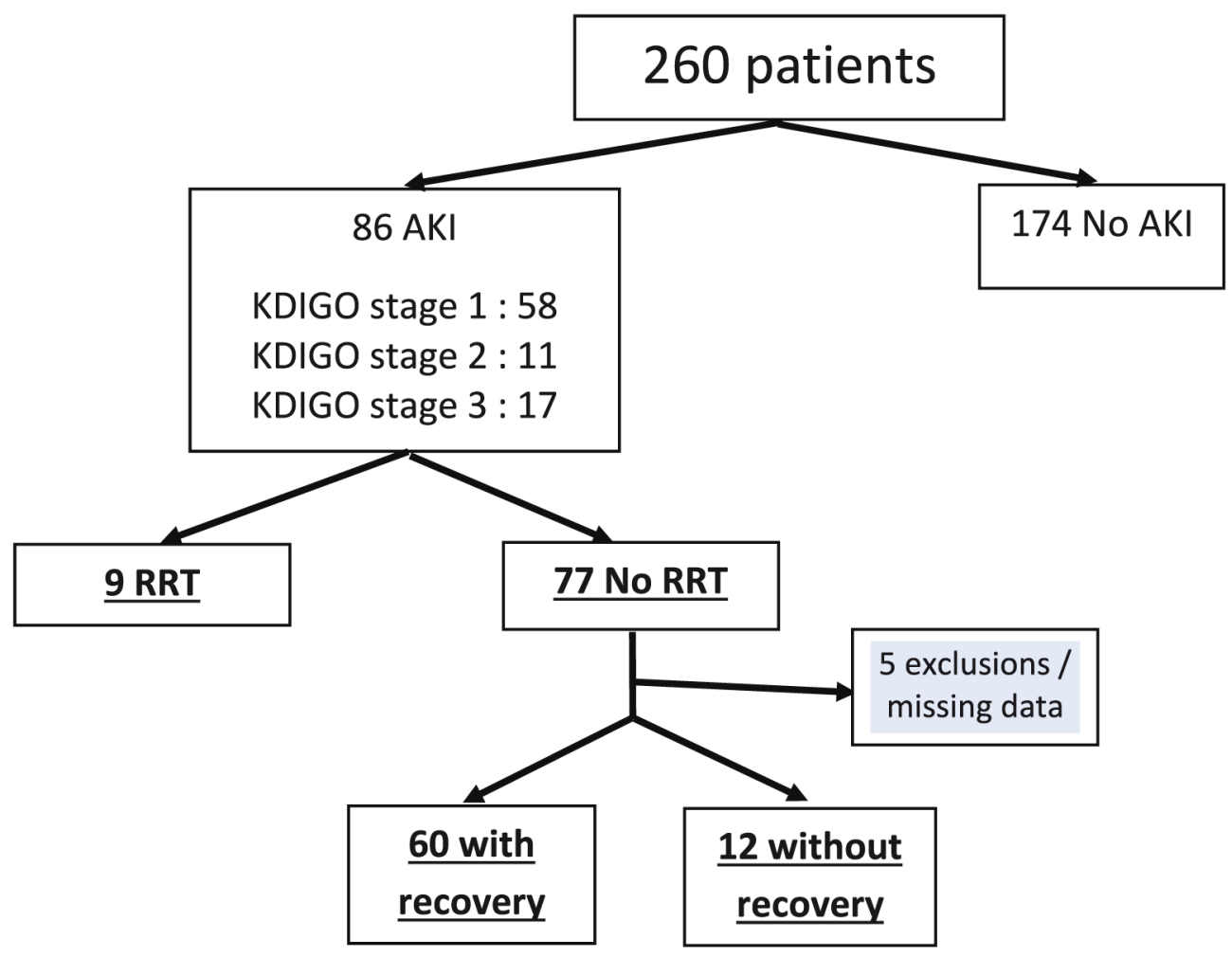

Fig 1. Study flowchart. AKI, acute kidney injury according to Kidney Disease Improving Global Outcomes (KDIGO) classification; RRT, renal replacement therapy. 
Table 1

Perioperative Characteristics

\begin{tabular}{|c|c|c|c|c|c|c|c|}
\hline \multirow[b]{2}{*}{ Age (y) } & \multicolumn{2}{|c|}{ Total $(n=260)$} & \multicolumn{2}{|c|}{ AKI $(n=86)$} & \multicolumn{2}{|c|}{ No AKI $(n=174)$} & \multirow{2}{*}{$\frac{\mathrm{p} \text { Value }}{0.32^{*}}$} \\
\hline & 69 & {$[59-76]$} & 70 & {$[62-77]$} & 69 & {$[59-76]$} & \\
\hline Male & 191 & $(73.5 \%)$ & 55 & $(64.0 \%)$ & 136 & $(78.2 \%)$ & $0.01^{\dagger}$ \\
\hline BMI & 26.6 & \pm 4.7 & 26.6 & \pm 5.0 & 26.6 & \pm 4.5 & $0.97^{\ddagger}$ \\
\hline \multicolumn{8}{|l|}{ Comorbidities } \\
\hline COPD & 47 & $(18.1 \%)$ & 23 & $(26.7 \%)$ & 24 & $(13.8 \%)$ & $0.01^{\dagger}$ \\
\hline Diabetes mellitus & 65 & $(25.0 \%)$ & 22 & $(25.6 \%)$ & 43 & $(24.7 \%)$ & $0.88^{\dagger}$ \\
\hline Hypertension & 132 & $(50.8 \%)$ & 46 & $(53.5 \%)$ & 86 & $(49.4 \%)$ & $0.54^{\dagger}$ \\
\hline LVEF $<30 \%$ & 14 & $(5.4 \%)$ & 11 & $(12.8 \%)$ & 3 & $(1.7 \%)$ & $<0.01^{\S}$ \\
\hline Peripheral vascular disease & 43 & $(16.5 \%)$ & 17 & $(19.8 \%)$ & 26 & $(14.9 \%)$ & $0.32^{\dagger}$ \\
\hline Right-sided heart failure/pulmonary hypertension & 8 & $(3.1 \%)$ & 5 & $(5.8 \%)$ & 3 & $(1.7 \%)$ & $0.12^{\S}$ \\
\hline EuroSCORE II (\%) & 2.5 & {$[1.4-5.6]$} & 6.7 & {$[3.1-12.6]$} & 1.8 & {$[1.1-3.6]$} & $<0.01^{*}$ \\
\hline \multicolumn{8}{|l|}{ Preoperative renal function } \\
\hline GFR $<60 \mathrm{~mL} / \mathrm{min} / 1.73 \mathrm{~m}^{2}$ & 86 & $(33.1 \%)$ & 42 & $(48.8 \%)$ & 44 & $(25.3 \%)$ & $<0.01^{\dagger}$ \\
\hline Serum creatinine $(\mu \mathrm{moL} / \mathrm{L})$ & 91.5 & {$[77-109]$} & 95 & {$[78-120]$} & 88 & [77-105] & $0.01^{*}$ \\
\hline Serum phosphate (mmoL/L) & 1.06 & [0.93-1.18] & 1.00 & {$[0.91-1.15]$} & 1.08 & [0.94-1.19] & $0.11^{*}$ \\
\hline \multicolumn{8}{|l|}{ Surgical characteristics } \\
\hline \multicolumn{8}{|l|}{ Surgery type } \\
\hline Valve surgery & 96 & $(36.9 \%)$ & 33 & $(38.4 \%)$ & 63 & $(36.2 \%)$ & $0.73^{\dagger}$ \\
\hline CABG & 122 & $(46.9 \%)$ & 31 & $(36.0 \%)$ & 91 & $(52.3 \%)$ & $0.01^{\dagger}$ \\
\hline Combined surgery & 82 & $(31.5 \%)$ & 36 & $(41.9 \%)$ & 46 & $(26.4 \%)$ & $0.01^{\dagger}$ \\
\hline Emergency surgery & 54 & $(20.8 \%)$ & 29 & $(33.7 \%)$ & 25 & $(14.4 \%)$ & $<0.01^{\dagger}$ \\
\hline $\mathrm{CPB}(\min )$ & 107 & {$[84-146.5]$} & 145 & {$[95-182]$} & 98 & {$[82-126]$} & $<0.01^{*}$ \\
\hline Aortic cross-clamping (min) & 80 & {$[62-107]$} & 99 & {$[72-136]$} & 72 & {$[59-98]$} & $<0.01 *$ \\
\hline Circulatory arrest $(\min )(n=10)$ & 46 & \pm 12 & 47 & \pm 13 & 42 & \pm 4 & $0.61^{\ddagger}$ \\
\hline Red blood cell transfusion & 57 & $(21.9 \%)$ & 34 & $(39.5 \%)$ & 23 & $(13.2 \%)$ & $<0.01^{\dagger}$ \\
\hline Vasopressors & 121 & $(46.7 \%)$ & 60 & $(69.8 \%)$ & 61 & $(35.3 \%)$ & $<0.01^{\dagger}$ \\
\hline Inotropes & 38 & $(14.7 \%)$ & 28 & $(32.6 \%)$ & 10 & $(5.8 \%)$ & $<0.01^{\dagger}$ \\
\hline \multicolumn{8}{|l|}{ Postoperative evolution } \\
\hline Red blood cell transfusion & 18 & $(6.9 \%)$ & 15 & $(17.4 \%)$ & 3 & $(1.7 \%)$ & $<0.01^{\dagger}$ \\
\hline Vasopressors & 63 & $(24.3 \%)$ & 53 & $(61.6 \%)$ & 10 & $(5.8 \%)$ & $<0.01^{\dagger}$ \\
\hline Inotropes & 25 & $(9.7 \%)$ & 24 & $(27.9 \%)$ & 1 & $(0.6 \%)$ & $<0.01^{\dagger}$ \\
\hline Mechanical ventilation in ICU (h) & 4 & {$[3-6]$} & 6 & [4-23] & 4 & {$[3-5]$} & $<0.01^{*}$ \\
\hline ICU length of stay (d) & 1 & {$[1-2]$} & 3 & {$[1-6]$} & 1 & {$[1-1]$} & $<0.01^{*}$ \\
\hline Hospital length of stay (d) & 9 & {$[7-14]$} & 14 & {$[10-21]$} & 8 & {$[7-10]$} & $<0.01^{*}$ \\
\hline Mortality & 8 & $(3.1 \%)$ & 8 & $(9.3 \%)$ & 0 & $(0.0 \%)$ & $<0.01^{\S}$ \\
\hline
\end{tabular}

NOTE. Quantitative data are expressed as mean \pm standard deviation or median [Q25-Q75] and were compared with the Student $t$ or Wilcoxon Mann-Whitney test, as appropriate. Categorical variables are expressed as the number of patients and percentage and were compared with the chi-square or Fisher exact test. Abbreviations: BMI, body mass index; CABG, coronary artery bypass grafting; COPD, chronic obstructive pulmonary disease; CPB, cardiopulmonary bypass; GFR, glomerular filtration rate; ICU, intensive care unit; LVEF, left ventricle ejection fraction.

* Compared with Wilcoxon Mann-Whitney test.

$\dagger$ Compared with chi-square test.

$\ddagger$ Compared with Student $t$ test.

$\S$ Compared with Fisher exact test.

In patients with preoperative CKD, AKI occurred in 42 (49\%) patients, with $28(32.6 \%)$ in AKI stage $1,8(9.3 \%)$ in AKI stage 2, and $6(7 \%)$ in AKI stage 3 (necessitated RRT).

\section{Primary Outcome: SPh Increase During AKI}

Preoperative $\mathrm{SPh}$ did not differ between AKI and noAKI patients, whereas preoperative $\mathrm{SCr}$ was greater in AKI patients than in no-AKI patients (see Table 1). In AKI patients, SPh increased significantly from the preoperative value until the peak, which occurred at 48 hours (24-60) (H48 peak) and was significantly greater at each postoperative day compared with no-AKI patients (Fig 3). In CKD AKI patients, $\mathrm{SPh}$ and $\mathrm{SCr}$ changes at 48 hours were similar during AKI (Table 2).

\section{Secondary Outcomes}

\section{SPh and AKI Severity}

The $\mathrm{H} 48$ peak of SPh demonstrated an excellent accuracy for the diagnosis of KDIGO stages 2 or 3, with an ROC AUC of 0.91 (95\% CI 0.83-1.00) and an Se of 88\%, an Sp of 86\%, a PPV of $45 \%$, and an NPV of $98 \%$, for a cutoff value of $1.33 \mathrm{mmol} / \mathrm{L}$. In this series, the $\mathrm{H} 48$ peak of $\mathrm{SCr}$ had an ROC AUC of 0.97 (95\% CI 0.92-1.00). The $\mathrm{SCr}$ and $\mathrm{SPh}$ ROC AUC tended to be different $(\mathrm{p}=0.055)(\mathrm{Fig} 4)$.

\section{SPh and AKI Recovery}

Among AKI patients without RRT $(\mathrm{n}=72)$, renal recovery was observed in 60 patients $(83 \%)$ and was more common in 


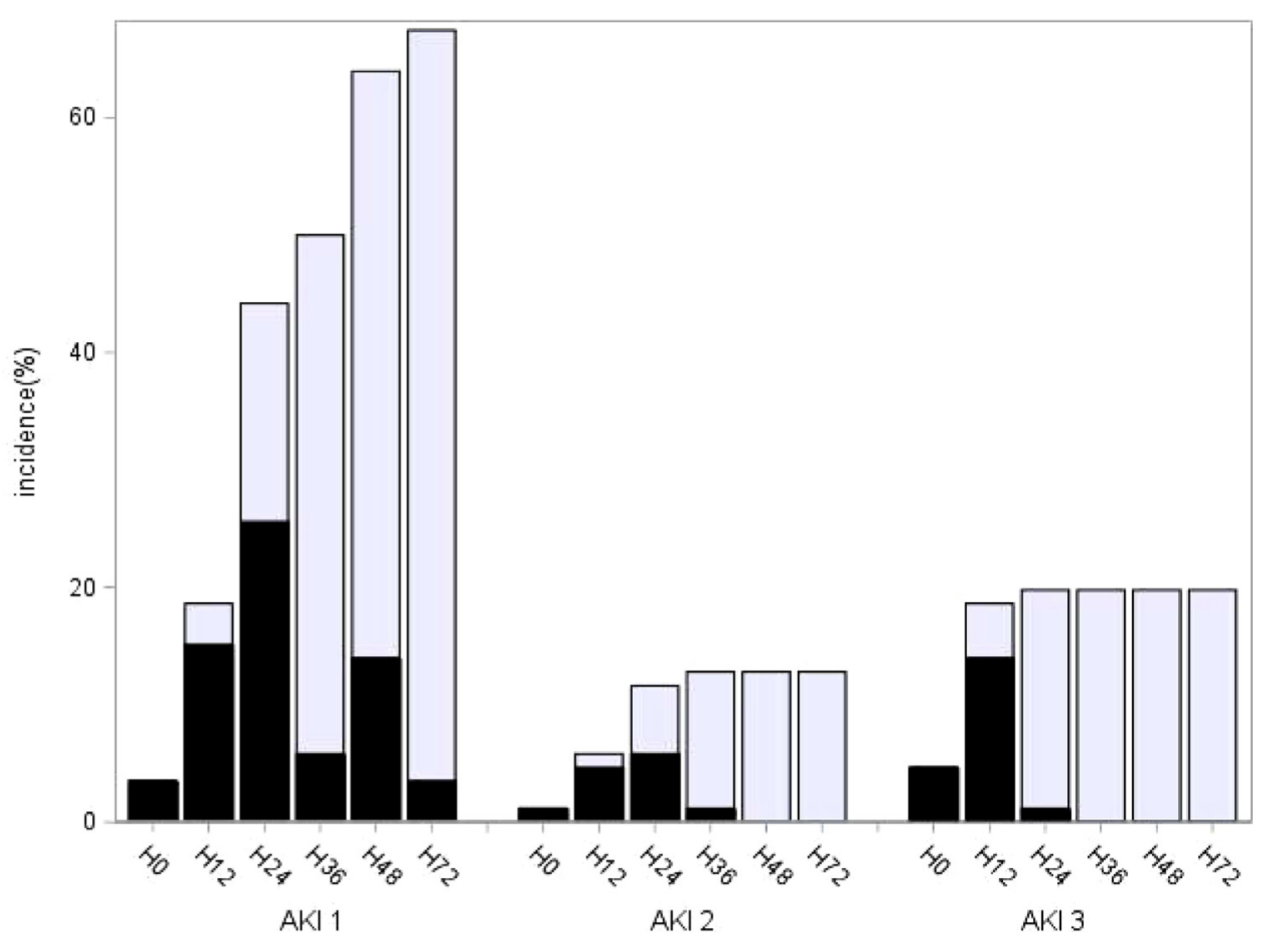

Fig 2. Acute kidney injury incidence over the first 3 postoperative days is represented by black bars and cumulative incidence by grey bars, grouped by acute kidney injury stages. Acute kidney injury, defined according to Kidney Disease Improving Global Outcomes stages, occurred early whatever its severity, with a maximal incidence at 24 hours for stages 1 and 2 and a maximal incidence at 12 hours for stage 3 . AKI, acute kidney injury; H, hour.

nonsevere AKI (stage 1) than in severe AKI (stages 1 and 2) $49(89 \%)$ patients versus $11(65 \%)$ patients, respectively; $\mathrm{p}=0.03$. The mortality rate was significantly greater in patients in whom renal function did not recover $(33 \%)$ compared with other patients $(5 \%)(\mathrm{p}=0.01)$.

Evolution of $\mathrm{SPh}$ and $\mathrm{SCr}$ in AKI patients over 7 days showed significant differences between patients who experienced kidney recovery compared with patients whose kidneys did not recover (Fig 5).

In renal recovery patients, $\mathrm{SPh}$ and $\mathrm{Scr}$ decreased significantly 24 hours after the $\mathrm{H} 48$ peak (Table 3); the SPh decrease tended to be more substantial than the $\mathrm{SCr}$ decrease $(\mathrm{p}=0.066)$ (see Fig 5).

The relative decreases of $\mathrm{SPh}$ and $\mathrm{SCr} 24$ hours after the $\mathrm{H} 48$ peak are reported in Table 3 along with the ROC curve analysis. Of note, a threshold of $-25 \% \mathrm{SPh}$ relative variation resulted in a $100 \%$ PPV value (Se $35.5 \%$, Sp $100 \%$, and NPV $35 \%$ ).

Using the cutoff values of SPh and SCr decrease, the authors calculated a net reclassification improvement of 10 patients of 24 who experienced an SCr decrease lower than the SCr cutoff value (details on reclassification improvement study in the Supplemental Material).

\section{Discussion}

To the authors' knowledge, the present study was the first detailed description of SPh evolution during AKI in adult cardiac surgery patients. SPh increase at the H48 peak parallels AKI severity, and SPh early decrease after the peak may help to predict renal recovery. Indeed, the $\mathrm{H} 48$ peak $\mathrm{SPh}$ value
$<1.33 \mathrm{mmol} / \mathrm{L}$ was associated with the absence of severe AKI, with an NPV of $98 \%$. A $25 \% \mathrm{SPh}$ decrease 1 day after the $\mathrm{H} 48$ peak demonstrated a PPV of $100 \%$ for renal recovery.

AKI remains one of the most common and serious clinical issues in the ICU and is associated with high morbidity and mortality. ${ }^{1,2}$ AKI in the context of cardiac surgery is specific because it may result from an acute but short injury related to surgery and $\mathrm{CPB} .{ }^{24}$ Identification of AKI at the early stage seems crucial for improving AKI management and AKI prognosis. ${ }^{3,25}$ Several investigations have been undertaken to identify biomarkers able to detect renal failure as early as possible. ${ }^{6-8,25}$ These biomarkers are promising for AKI diagnosis and severity but do not help to describe AKI evolution. SCr is used to diagnose and classify AKI according to $\mathrm{KDIGO}^{3,15}$; however, SCr may not be a good biomarker of early AKI evolution. ${ }^{26} \mathrm{SPh}$, which has a homeostasis strongly regulated by the kidneys, has not been studied thoroughly during AKI. ${ }^{13}$ In the present study, SPh showed paralleled evolution to SCr. It is noticeable that preoperative $\mathrm{SCr}$ was greater in AKI patients than in no-AKI patients, whereas $\mathrm{SPh}$ was in the same normal range in both groups. However, acute changes in $\mathrm{SPh}$ and $\mathrm{SCr}$ during AKI were similar in non-CKD patients and CKD patients. Therefore, $\mathrm{SPh}$ is neither an early marker of AKI nor a specific marker of AKI in CKD patients. Conversely, SPh showed good accuracy for AKI severity diagnosis, with ROC AUC values around 0.9, not much less than those for $\mathrm{SCr}(0.97)$, the gold standard of KDIGO definition. Similar findings on $\mathrm{SPh}$ correlation with disease severity have been observed in CKD patients. A significant increase in $\mathrm{SPh}$ has been independently associated with declines in renal function and dialysis requirement and cardiovascular events. ${ }^{20,27}$ Indeed, hyperphosphatemia, which develops inevitably at end-stage CKD, points out a significant 


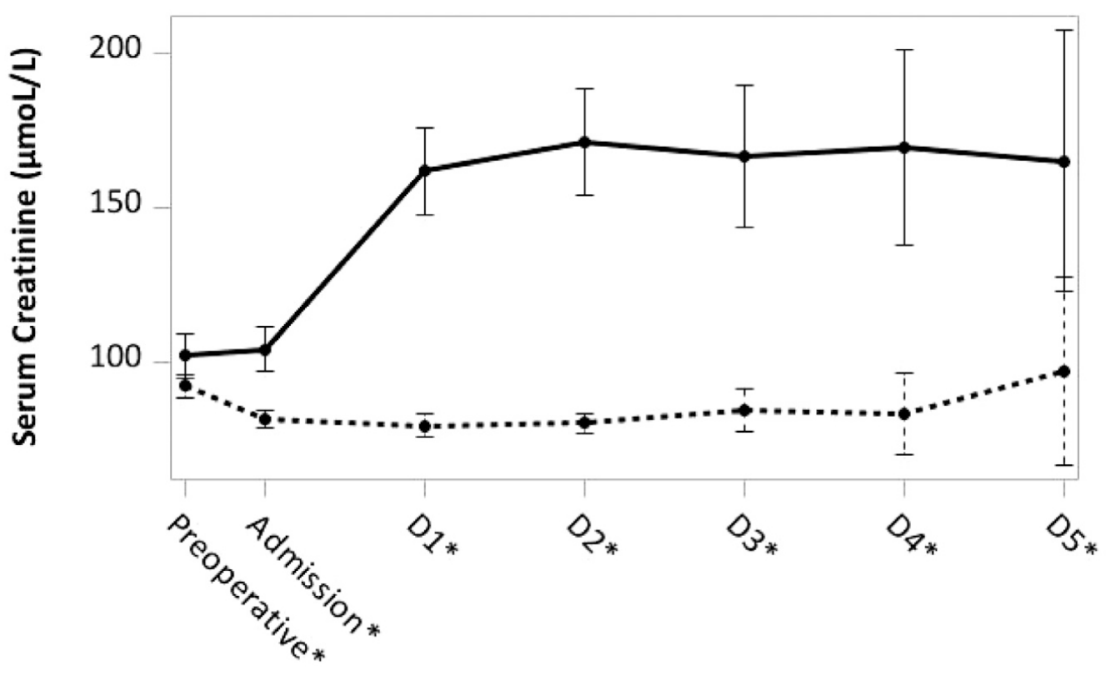

Days

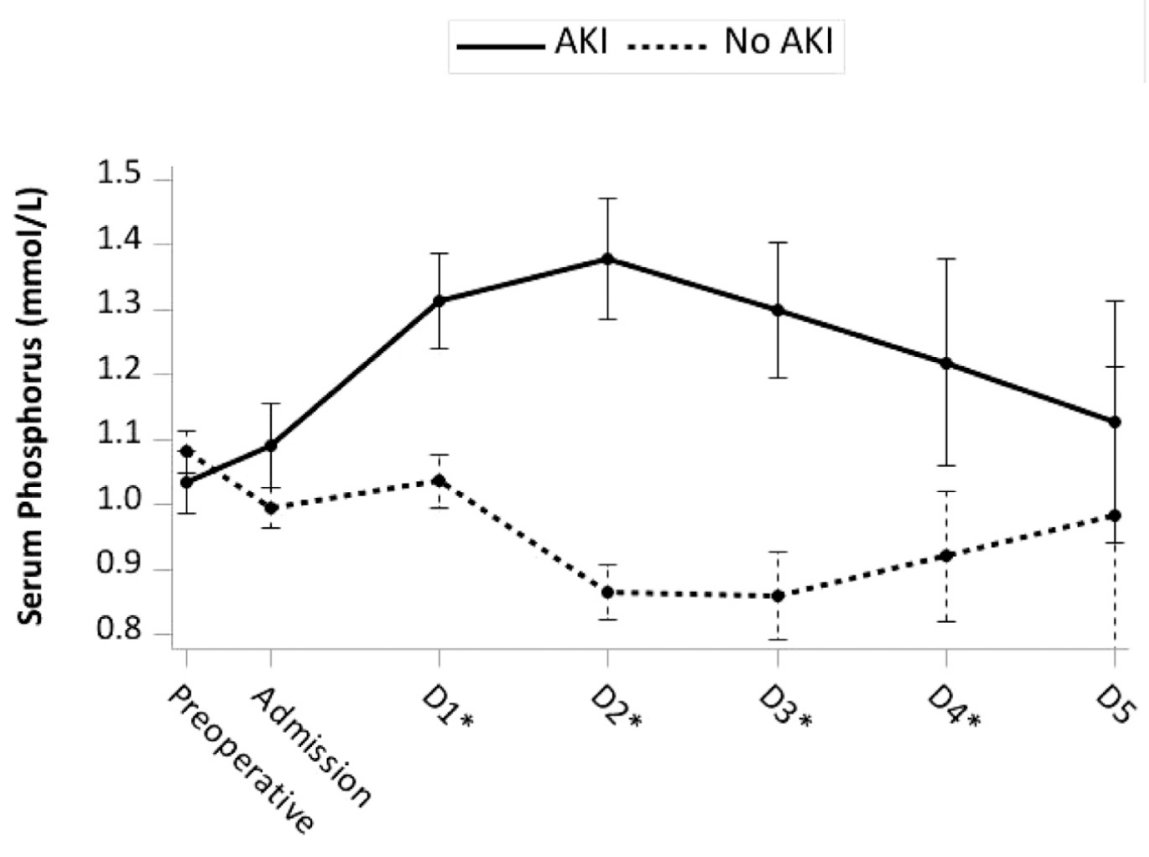

Days

Fig 3. Serum creatinine (upper panel) and serum phosphate (lower panel) mean \pm standard deviation over the first 5 days after surgery in acute kidney injury patients and no-acute kidney injury patients. In acute kidney injury patients, serum phosphate and serum creatinine increased from the preoperative value until the 48-hour peak and appeared significantly different from that of no-acute kidney injury patients after Holm's correction (*). AKI, acute kidney injury; D, day.

change in the prognosis of the disease because it correlates with death. ${ }^{18-20}$ The present study suggested that $\mathrm{SPh}$ correelates with kidney disease severity, as it already has been reported in AKI of various causes. ${ }^{28}$ Conversely, the good correlation between SPh and AKI severity allows for the anticipation that AKI will not be severe if the SPh peak value at 48 hours after surgery is less than $1.33 \mathrm{mmol} / \mathrm{L}$.

Taking for granted that an $\mathrm{SPh}$ increase correlates with AKI severity, an SPh decrease after its $\mathrm{H} 48$ peak could provide important information on renal recovery. The authors are aware that the present study's arbitrary definition of renal recovery had at least 2 restrictions. First it depended on $\mathrm{SCr}$, and $\mathrm{SCr}$ may not be accurate to assess renal function recovery after $\mathrm{AKI}{ }^{26}$ Second, renal recovery was assessed at hospital discharge, meaning within 1- to- 2 weeks after AKI. This short-term evaluation may have missed late recovery because various patterns of renal recovery are possible. ${ }^{29-31}$ Nevertheless, it is noticeable that renal recovery started early, within 24 hours after the $\mathrm{SCr}$ peak. However, SCr declined slowly, and its early decrease was not excellent for predicting renal recovery, as assessed by the ROC curve analysis, although it is the 
Table 2

Serum Phosphate and Serum Creatinine Comparisons in AKI Versus Non-AKI Among CKD Status

\begin{tabular}{|c|c|c|c|c|c|c|}
\hline & $\begin{array}{l}\text { CKD }(n=86) \\
\text { No-AKI }(n=44)\end{array}$ & $\mathrm{AKI}(\mathrm{n}=42)$ & $\mathrm{p}$ & $\begin{array}{l}\text { Non-CKD }(\mathrm{n}=174) \\
\text { No-AKI }(\mathrm{n}=130)\end{array}$ & $\mathrm{AKI}(\mathrm{n}=44)$ & $\mathrm{p}$ \\
\hline \multicolumn{7}{|l|}{ Serum creatinine } \\
\hline \multirow[t]{2}{*}{ Serum phosphatePreoperative value $(\mu \mathrm{moL} / \mathrm{L})$} & $(\mathrm{n}=44)$ & $(\mathrm{n}=42)$ & & $(\mathrm{n}=129)$ & $(\mathrm{n}=43)$ & \multirow[t]{2}{*}{$0.607 *$} \\
\hline & $116.5[105.0-125.5]$ & $120.0[103.0-139.0]$ & $0.531 *$ & $81.0[74.0-93.0]$ & $85.0[70.0-93.0]$ & \\
\hline Serum phosphateRelative variation (\%) & $\begin{array}{l}(\mathrm{n}=23) \\
-15.7[-22.3 \text { to }-6.7]\end{array}$ & $\begin{array}{l}(\mathrm{n}=32) \\
33.8[18.5-87.0]\end{array}$ & $<0.001$ & $\begin{array}{l}(\mathrm{n}=126) \\
-11.8[-19.5 \text { to }-3.9]\end{array}$ & $\begin{array}{l}(\mathrm{n}=40) \\
48.3[23.5-125.0]\end{array}$ & $<0.001 \dagger$ \\
\hline \multicolumn{7}{|l|}{ Serum phosphate } \\
\hline \multirow[t]{2}{*}{ Preoperative value $(\mu \mathrm{moL} / \mathrm{L})$} & $(\mathrm{n}=29)$ & $\mathrm{n}=34$ & & $(\mathrm{n}=107)$ & $(\mathrm{n}=29)$ & \multirow[t]{2}{*}{$0.704 *$} \\
\hline & $\begin{array}{l}1.1[1.0-1.2] \\
(\mathrm{n}=23)\end{array}$ & $\begin{array}{l}1.0[0.9-1.1] \\
(\mathrm{n}=32)\end{array}$ & $0.038 *$ & $\begin{array}{l}1.1[0.9-1.2] \\
(\mathrm{n}=81)\end{array}$ & $\begin{array}{l}1.0[0.9-1.2] \\
(\mathrm{n}=25)\end{array}$ & \\
\hline Serum phosphateRelative variation (\%) & $-7.5( \pm 17.4)$ & $40.6( \pm 33.6)$ & $<0.001 \ddagger$ & $-26.1[-40.6$ to -11.2$]$ & $37.6[13.2-66.0]$ & $<0.001 *$ \\
\hline
\end{tabular}

NOTE. Quantitative data are expressed as mean ( \pm standard deviation) or median [Q25-Q75] and were compared with the Wilcoxon Mann-Whitney (*) or Student $t$ test $(\ddagger)$ or the test, as appropriate. $\nmid p$ values are comparisons between AKI and no-AKI.

Abbreviations: AKI, acute kidney injury; CKD, chronic kidney disease, defined as preoperative EPI-eGFR (EPIdemiology-estimated GFR) $<60 \mathrm{~mL} / \mathrm{m} / 1.73 \mathrm{~m}{ }^{2}$ (variation at 48 hours: [value at hour 48 - preoperative value]/preoperative value); IRA, xxx.

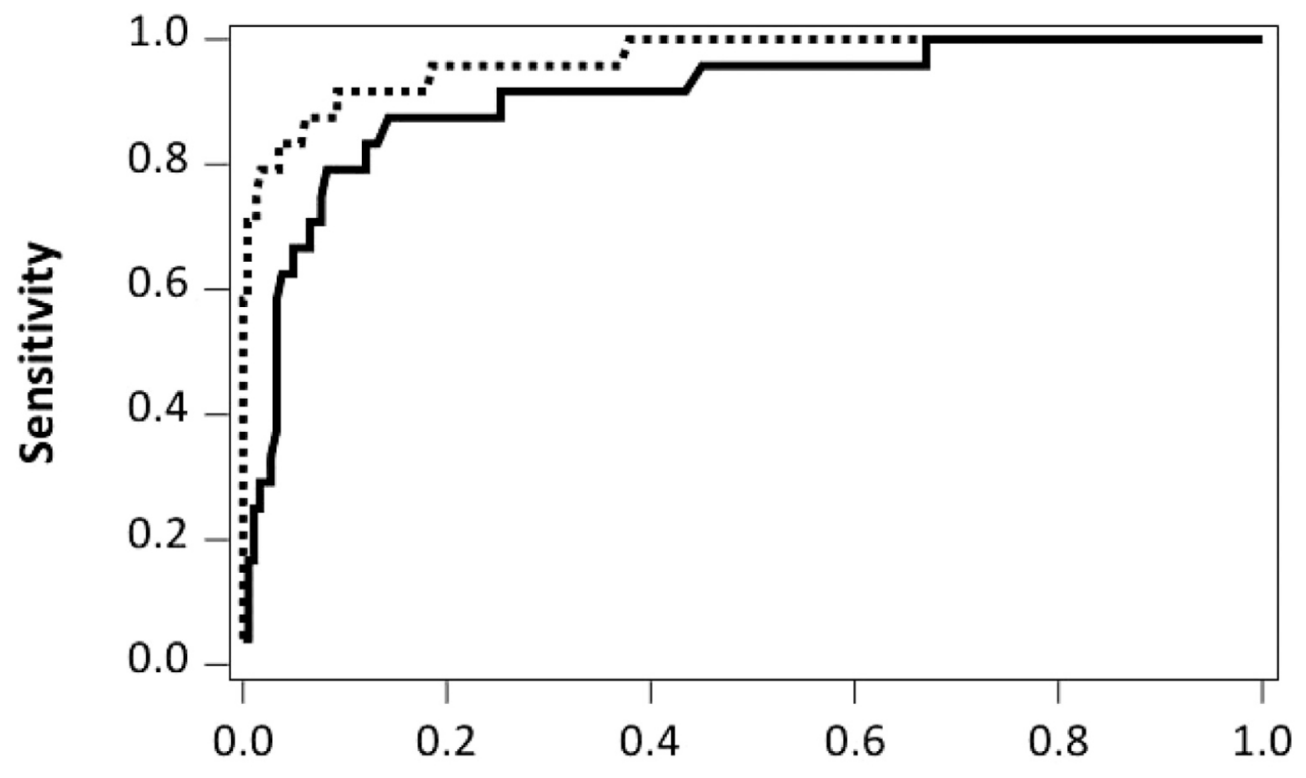

1-Specificity

\section{Serum Phosphorus ...... Serum Creatinine}

Fig 4. The receiver operating characteristic curve of serum phosphate and serum creatinine at 48 hours for Kidney Disease Improving Global Outcomes stages 2 or 3 diagnosis.

reference criterion. The percent decrease of SPh 24 hours after the $\mathrm{H} 48$ peak was 2.5 times greater than the percent decrease of SCr. The ROC AUC of the SPh decrease was not better than that of $\mathrm{SCr}$, but 2 points recommended $\mathrm{SPh}$ monitoring during renal recovery. First, the SPh decrease helped to reclassify $42 \%$ of AKI patients for whom the $\mathrm{SCr}$ decrease was less than the SCr cutoff value predictive of renal recovery. Second, a probability of $100 \%$ recovery had been observed if the SPh decrease 24 hours after the H48 peak exceeded $25 \%$. Taken together, these results suggested that $\mathrm{SPh}$ could be considered as a useful biomarker of AKI severity and evolution after cardiac surgery.
This study had several limitations. First, it was a monocentric, observational study. Second, the authors chose not to report other electrolytic disorders during AKI such as serum $\mathrm{pH}$, calcemia, and bicarbonate. The study was not designed to address the issue of AKI's effect on all electrolytes but to focus on SPh kinetics as was done previously in CKD. In addition, SPh perioperative changes were independent of dietary or external intake because there were no potential medical interventions except the use of RRT when appropriate. Third, results on renal recovery were based on a small number of patients, which may have limited the statistical power of this specific analysis. Fourth, 260 patients were 


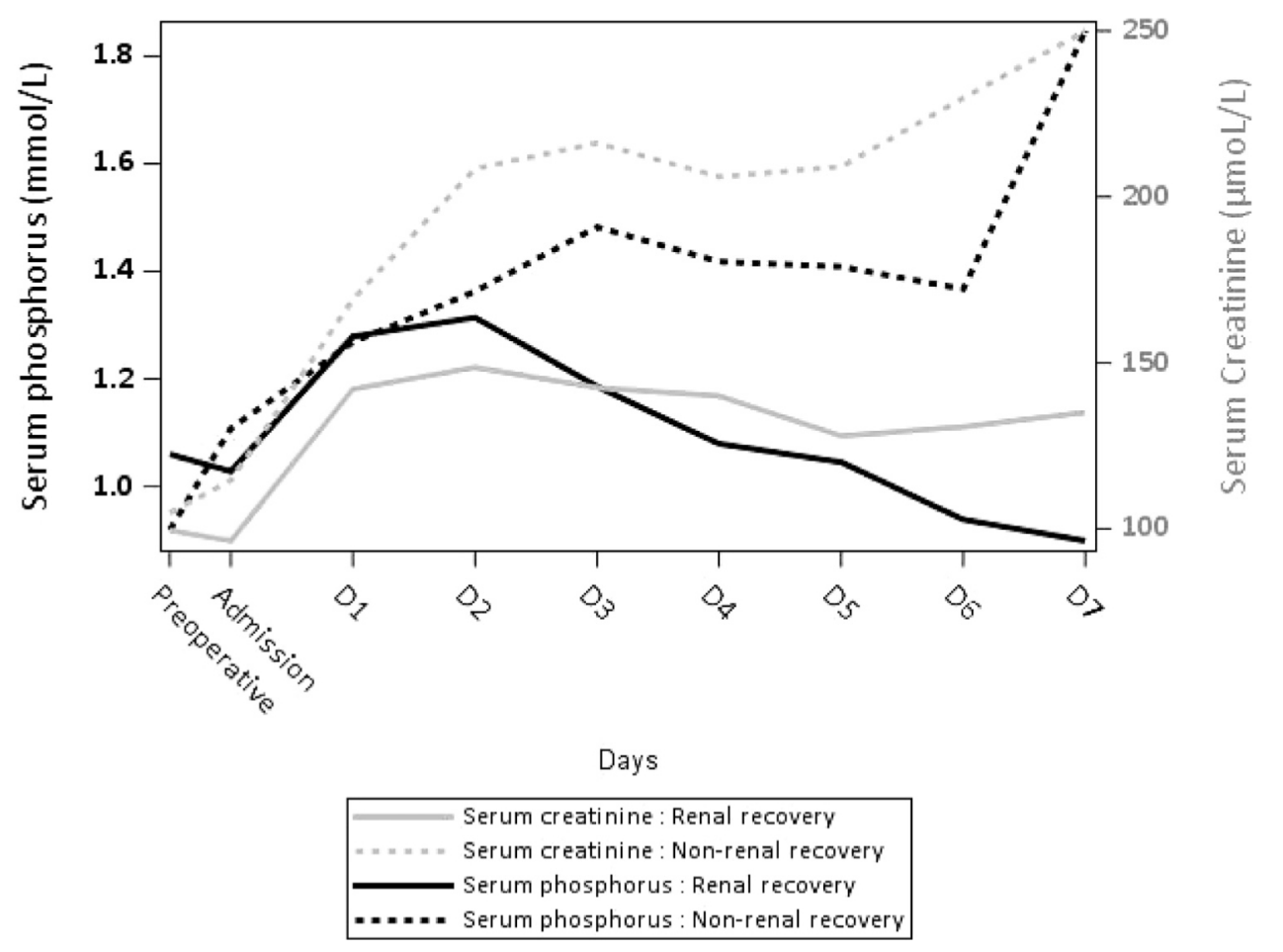

Fig 5. Follow-up over 7 postoperative days of serum phosphate and serum creatinine levels in acute kidney injury patients. Serum creatinine and serum phosphate are expressed as the mean in acute kidney injury patients over the first 7 days after surgery in kidney recovery and non-kidney recovery patients. The serum phosphate changes 24 hours after the 48-hour peak were $-12.4 \%( \pm 23.9)$ in renal recovery patients, whereas it increased by $12.6 \%( \pm 25.7)$ in non-renal recovery patients $(\mathrm{p}=0.007)$. Kinetic of serum creatinine showed similar significant variations between groups but with a slope less steep than for serum phosphate. $\mathrm{D}$, day.

Table 3

Relative Variation of Serum Phosphate and Serum Creatinine 24 Hours After the 48-Hour Peak in AKI Patients

\begin{tabular}{lll}
\hline $\begin{array}{l}\text { Relative Variation Between } \\
48 \mathrm{~h} \text { and } 72 \mathrm{~h}(\%)\end{array}$ & $\mathrm{SCr}$ \\
\hline Renal recovery patients & $-12.4 \%( \pm 23.9)$ & $-7.8 \%[-18.9$ to 1.7$]$ \\
No renal recovery patients & $12.6 \%( \pm 25.7)$ & $4.5 \%[-5.0$ to 16.0$]$ \\
$\quad \mathrm{p}$ value & $0.007 *$ & $0.016 \dagger$ \\
ROC analysis & & \\
AUC [95\% CI] & $0.76 \%[0.62-0.91]$ & $0.74 \%[0.60-0.89]$ \\
Threshold & $-2.5 \%$ & $-6.4 \%$ \\
Se & $69.8 \%$ & $54.7 \%$ \\
Sp & $77.8 \%$ & $90.0 \%$ \\
PPV & $93.8 \%$ & $96.7 \%$ \\
NPV & $35.0 \%$ & $27.3 \%$ \\
\hline
\end{tabular}

NOTE. Quantitative data are expressed as mean ( \pm standard deviation) or median [Q25-Q75] and were compared between the 2 groups (renal $v$ no renal recovery) with the Student $t\left({ }^{*}\right)$ or Wilcoxon Mann-Whitney $(\dagger)$ test, as appropriate.

Abbreviations: AKI, acute kidney injury; AUC, area under the curve; CI confidence interval; NPV, negative predictive value; PPV, positive predictive value; $\mathrm{ROC}$, receiver operating characteristic; $\mathrm{SCr}$, serum creatinine; Se, sensitivity; Sp, specificity; $\mathrm{SPh}$, serum phosphate.

in the study, slightly fewer than expected (264), but this affected the statistical power only marginally. Finally, the effect of the extent of SPh increase or decrease during AKI is unknown on long-term outcome.

\section{Conclusion}

$\mathrm{SPh}$ behaves as an interesting AKI biomarker, with the major asset of being easily available in daily practice. Nevertheless, additional studies are required to evaluate the effect of $\mathrm{SPh}$ kinetics, combined with $\mathrm{SCr}$ changes, on clinical decision-making regarding AKI management.

\section{Conflict of Interest}

None.

\section{References}

1 Uchino S, Kellum JA, Bellomo R, et al. Beginning and Ending Supportive Therapy for the Kidney Investigators. Acute renal failure in critically ill patients: A multinational, multicenter study. JAMA 2005;29:813-8.

2 Chertow GM, Burdick E, Honour M, et al. Acute kidney injury, mortality, length of stay, and costs in hospitalized patients. J Am Soc Nephrol 2005; 16:3365-70.

3 Lassnigg A, Schmidlin D, Mouhieddine M, et al. Minimal changes of serum creatinine predict prognosis in patients after cardiothoracic surgery: A prospective cohort study. J Am Soc Nephrol 2004;15:1597-605.

4 Thakar CV, Arrigain S, Worley S, et al. A clinical score to predict acute renal failure after cardiac surgery. J Am Soc Nephrol 2005;16:162-8. 
5 Wijeysundera DN, Karkouti K, Dupuis JY, et al. Derivation and validation of a simplified predictive index for renal replacement therapy after cardiac surgery. J Am Med Assoc 2007;297:1801-9.

6 Haase-Fielitz A, Bellomo R, Devarajan P, et al. Novel and conventional serum biomarkers predicting acute kidney injury in adult cardiac surgery-a prospective cohort study. Crit Care Med 2009;37:553-60.

7 Haase M, Bellomo R, Devarajan P, NGAL Meta-analysis Investigator Group. Accuracy of neutrophil gelatinase-associated lipocalin (NGAL) in diagnosis and prognosis in acute kidney injury: A systematic review and meta-analysis. Am J Kidney Dis 2009;54:1012-24.

8 Jia HM, Huang LF, Zheng Y, et al. Diagnostic value of urinary tissue inhibitor of metalloproteinase-2 and insulin-like growth factor of binding protein 7 for acute kidney injury: A meta-analysis. Crit Care 2017;21:77.

9 Perry T, Muehischlegel J, Liu KY, CABG Genomic Investigators. Plasma neutrophil gelatinase-associated lipocalin and acute postoperative kidney injury in adult cardiac surgical patients. Anesth Analg 2010;110:1541-7.

10 Srisawat N, Murugan R, Lee M, et al. Plasma neutrophil gelatinase-associated lipocalin predicts recovery from acute kidney injury following community-acquired pneumonia. Kidney Int 2011;80:545-52.

11 Meersch M, Schmidt C, Van Aken H, et al. Urinary TIMP-2 and IGFBP7 as early biomarkers of acute kidney injury and renal recovery following cardiac surgery. Plos One 2014;9:e93460.

12 Chawla L, Bellomo R, Bihorac A, Acute Disaese Quality Initiative Workgroup 16. Acute kidney disease and renal recovery: Consensus report of the Acute Disease Quality Initiative (ADQI) 16 Workgroup. Nephrol 2017;13:241-57.

13 Blaine J, Chonchol M, Levi M. Renal control of calcium, phosphate and magnesium homeostasis. Clin J Am S Nephrol 2015;10:1257-72.

14 Macedo E, Bouchard J, Soroko SH, et al. Fluid accumulation, recognition and staging of acute kidney injury in critically-ill patients. Crit Care 2010;14:R82.

15 Kidney Disease: Improving Global Outcomes. Clinical practice guideline for acute kidney injury. Kidney Int 2012:(Suppl 2):1-13.

16 Bjornsson TD. Use of serum creatinine concentrations to determine renal function. Clin Pharmacokinet 1979;4:200-22.

17 Farrow EG, White KE. Recent advances in renal phosphate handling. Nat Rev Nephrol 2010;6:207-17.

18 Hsu C, Chertow GM. Elevations of serum phosphorus and potassium in mild to moderate chronic renal insufficiency. Nephrol Dial Transplant 2002;17:1419-25.
19 Voormolen N, Noordzij M, Grootendorst DC, PREPARE Study Group. High plasma phosphate as a risk factor for decline in renal function and mortality in pre-dialysis patients. Nephrol Dial Transplant 2007;10:2909_ 16.

20 Bellasi A, Mandreoli M, Baldrati L, et al. Chronic kidney disease progression and outcome according to serum phosphorus in mild-to-moderate kidney dysfunction. Clin J Am Soc Nephrol 2011;6:883-91.

21 Cohen J, Kogan A, Sahar G, et al. Hypophosphatemia following openheart surgery: Incidence and consequences. Eur J Cardiothorac Surg 2004;26:306-10.

22 Chalmers J, Pullan M, Fabri B, et al. Validation of EuroSCORE II in a modern cohort of patients undergoing cardiac surgery. Eur J Cardiothorac Surg 2013;43:688-94.

23 Le Gall JR, Lemeshow S, Saulnier F. A new Simplified Acute Physiology Score (SAPS II) based on a European/North American multicenter study. JAMA 1993;270:2957-63.

24 Kumar A, Suneja MD. Cardiopulmonary bypass associated acute kidney injury. Anesthesiology 2011;4:964-70.

25 Meersch M, Schmidt C, Hoffmeier A, et al. Prevention of cardiac surgeryinduced AKI by implementing the KDIGO guidelines in high risk patients identified by biomarkers: The PreAKI randomized clinical trial. Intensive Care Med 2017;43:1551-61.

26 Schetz M, Gunst J, Van den Berghe G. The impact of using GFR versus creatinine clearance on the evaluation of recovery from acute kidney injury in the ICU. Intensive Care Med 2014;11:109-17.

27 Palmer SC, Hayen A, Macaskill P, et al. Serum levels of phosphorus, parathyroid hormone and calcium risks of death and cardiovascular disease in individuals with chronic kidney disease: A systematic review and meta analysis. JAMA 2011;305:1119-27.

28 Jung SY, Kwon J, Park S, et al. Phosphate is a potential biomarker of disease severity and predicts adverse outcomes in acute kidney injury patients undergoing continuous renal replacement therapy. Plos One 2018;7;13: e0191290.

29 Forni LG, Darmon M, Ostermann M, et al. Renal recovery after acute kidney injury. Intensive Care Med 2017;43:855-66.

30 Kellum JA, Sileanu FE, Bihorac A, et al. Recovery after acute kidney injury. Am J Respir Crit Care Med 2017;195:784-91.

31 Helgadottir S, Sigurdsson M, Palsson R, et al. Renal recovery and longterm survival following acute kidney injury after coronary artery surgery: A nationwide study. Acta Anaesth Scand 2016;9:1230-40. 